Article

\title{
Statistics on Nonmigrating Diurnal Tides Generated by Tide-Planetary Wave Interaction and Their Relationship to Sudden Stratospheric Warming
}

\author{
Xiaojuan Niu ${ }^{1}$, Jian $\mathrm{Du}^{2, *}$ and Xuwen $\mathrm{Zhu}{ }^{3}$ \\ 1 Department of Physics, Jianghan University, Wuhan 430000, China; meteorniu@126.com \\ 2 Department of Physics and Astronomy, University of Louisville, Louisville, KY 40292, USA \\ 3 Department of Mathematics, University of Louisville, Louisville, KY 40292, USA; xuwen.zhu@louisville.edu \\ * Correspondence: jian.du@louisville.edu; Tel.: +1-502-852-0919
}

Received: 4 September 2018; Accepted: 20 October 2018; Published: 25 October 2018

check for updates

\begin{abstract}
The nonmigrating diurnal tide, DW2, is known to have a source from the stationary planetary wave with wavenumber 1 (SPW1) and the migrating diurnal tide (DW1) interaction. Recent research has shown that DW2 time evolution in the equatorial mesopause tracks very well with SPW1 in the polar stratosphere for the winter of 2009-2010, which contains a sudden stratospheric warming (SSW) vortex split event. This paper extends previous research and investigates the relationship between these two waves for 31 winters from 1979 to 2010 with the extended Canadian Middle Atmosphere Model (eCMAM) through correlation and composite analysis. Significant correlations are present between the two waves in 20 out of 31 winters (65\%). We separate the 31 winters into four categories: SSW-displacement, SSW-split, minor-SSW, and no-SSW. Our results show that there is no significant difference among the four categories in terms of correlations between the two waves. Although SPW1 is usually stronger during a SSW-D winter, this does not warrant a stronger interaction with DW2.
\end{abstract}

Keywords: nonlinear interaction; sudden stratospheric warming; planetary waves; atmospheric tides

\section{Introduction}

It is becoming increasingly clear that understanding wave driving from below is critical for predicting large and small scale structures in the ionosphere and thermosphere (IT) system, such as ionospheric scintillations important to communication and navigation, and testing and improving models for orbit propagation and collision warnings. However, the relevant coupling processes operating within the neutral atmosphere, and between the neutral atmosphere and ionosphere, involve a host of multi-scale dynamics that are not fully understood at present [1]. Atmospheric tide is one of the key players for inducing the multi-scale dynamics in the IT system. Owing to rotation of the planet, periodic absorption of solar radiation in local time (LT) and longitude (e.g., by troposphere $\mathrm{H}_{2} \mathrm{O}$ and stratosphere $\mathrm{O}_{3}$ ) excites a spectrum of thermal tides having periods and zonal (east-west) wavenumbers (or harmonics) defined by the planetary rotation period and longitudinal variability, respectively. Solar heating can be approximated by a rectified cosine profile so that Fourier transformation can be used to decompose the tidal components into periods of sub-harmonics of a solar day: Diurnal $(24 \mathrm{~h})$, semidiurnal $(12 \mathrm{~h})$, and terdiurnal $(8 \mathrm{~h})$ etc. Tides can be allotted into two distinct categories, migrating and nonmigrating tides. Migrating (sun-synchronous) tides propagate westward with the apparent motion of the Sun. Nonmigrating tides do not follow the apparent motion of the Sun and can propagate westward, eastward, or be stationary. Different tidal components are identified as follows: "DWs" or "Des" denotes a westward or eastward propagating diurnal tide, 
respectively, with zonal wave number, s. The standing oscillation of a $24 \mathrm{~h}$ period is denoted as DS0. Of these tidal components, DW1 is the migrating tide and the rest are nonmigrating tides. In this paper, we focus on the nonmigrating diurnal tide-DW2.

Tidal variability has been observed to occur on time scales ranging from days [2] to years [3], and may arise due to a variety of factors. The possible causes have not been clearly sorted out, but are generally thought to fall into three categories: (1) variability of tropospheric and/or stratospheric tidal sources [3]; (2) propagation modulation due to altered background mean wind [4]; and (3) nonlinear interaction with planetary waves [5] and possibly gravity waves [6].

Short-term variability (periods $<30$ days) of atmospheric tides have regularly been observed to fluctuate in amplitude at periodicities similar to those of planetary waves (from quasi-two-day to quasi-stationary) presenting at the same time, indicative of a nonlinear interaction between the migrating tide and the planetary waves [7,8]. Teitelbaum and Vial (1991) [5] proposed that nonlinear coupling between the migrating tides and stationary planetary waves can also generate nonmigrating tides, which are the child waves that have frequencies and wavenumbers equal to the sum and difference of those of the parent waves. Observed correlations between the migrating tides and planetary wave activity provide evidence for this mechanism [7-10]; modeling studies have also shown that this interaction can produce nonmigrating tides with large amplitudes [11-14].

Despite the above studies, it was also noted that the global distribution of the nonmigrating tides in the lower thermosphere showed a strong sensitivity to the background zonal mean zonal wind profile [15], and the planetary-wave-induced background atmosphere changes can drive tidal variability at levels greater than tidal/planetary wave interaction [16]. Xu et al. (2009) [17] questioned the time scales of the strong correlations between the planetary wave and the nonmigrating tides seen within the observations. Their results showed that the strong correlation in their multi-site radar observations is contributed to largely by the low frequency fluctuations ( $>15$ days). Du et al. (2014) [18] examined the global-scale correlations of the amplitudes of the migrating tides, DW1/SW2, and the stationary planetary wave 1 (SPW1) and the assumed "child" nonmigrating tides. The results indicate that the correlations are highly time scale-dependent and the significant correlations seen with the original time series are mainly due to longer-term variations ( $>18$ days). There are no consistent global correlations associated with the short-term variations ( $<18$ days) among these waves.

Major sudden stratospheric warmings (SSWs) involve anomalous planetary wave propagation and dissipation in the polar stratosphere, which typically increase the temperature of the stratosphere by as much as $40-50 \mathrm{~K}$ in just a few days [19]. While the relationship between the planetary wave activity and the SSWs is well studied, the one for the tidal activity, unfortunately, is still poorly understood. Although quasi-stationary planetary waves are generally trapped below mesopause, and through the interaction with the tides, the impact of the SSWs can be felt well into the IT region, and even tropical ionosphere [20-27]. Pedatella and Forbes (2010) [23] suggest that planetary wave-tide interactions are the primary mechanism coupling SSWs to ionospheric variability.

During an SSW event, the polar vortex generally deforms into one of the two distinctly different ways. The first is when the vortex drifts away from the pole toward lower latitudes. This is known as a "displacement" type event. The other type of events is when the vortex is split into two smaller vortexes and each of these drifts separately away from the pole before dissipating, such events are known as split type events. For example, the 2006 warming is characterized as a "vortex displacement" and the 2009 warming as a "vortex split". Often a correlation is made between the type of planetary waves that caused the SSW and the type of event: If the waves which cause the event are mostly of wavenumber 1 , it is a displacement event, and if they are wavenumber 2, it is a split event [28].

The anomalous strong planetary wave activity during SSWs provides excellent opportunity to study tidal/planetary wave interaction. For example, the nonmigrating diurnal components (child waves: DS0 and DW2) are generated from the nonlinear interaction between the SPW1 and the migrating diurnal tide DW1 [12]. Indeed, Leiberman et al. (2015) [8] presented clear evidence that in 
the winter of 2009-2010 (a split SSW event), the DW2 temperature amplitude evolution appears to track the SPW1 amplitudes (Figure 8 of their paper).

The main objective of this paper is to examine: (1) Does DW2 and SPW1 amplitudes track each other in every winter, or is the 2009-2010 winter just an exception? (2) Does SSW types govern the relationship between DW2 and SPW1 in any way? For an SSW-displacement event, SPW1 tends to be stronger; does this mean a stronger correlation between DW2 and SPW1? We use a 31.5-year run (1979-2010) from the extended Canadian Middle Atmospheric Model (eCMAM) to answer the above two questions. We first calculate the correlation coefficients between DW2 and SPW1 for all 31 winters then classify the 31-winters into four categories: SSW-D (displacement), SSW-S (split), minor-SSW, no-SSW, and investigate if a stronger interaction is observed between DW2 and SPW1 during SSW-D winters when SPW1 is supposed to be stronger than usual. The paper is arranged as follows. Section 2 gives an introduction of the model. Section 3 shows the main results of our findings. Section 4 presents the discussion and Section 5 is the conclusions.

\section{Data and Model}

The eCMAM [29-32] has a top at $2 \times 10^{-7} \mathrm{hPa}$, which is geopotential height at $220 \mathrm{~km}$, but is dependent on the solar cycle. The new version of the model is enhanced by the inclusion of neutral and ion chemistry. The model has a triangular spectral truncation of T32, corresponding to a $6^{\circ}$ horizontal grid. There are 87 levels in the vertical, and the resolution varying from several tens of meters in the lower troposphere to $\sim 2.5 \mathrm{~km}$ in the mesosphere and thermosphere. The model includes the non-local thermal equilibrium (LTE) parameterization for the $15 \mu \mathrm{m} \mathrm{CO}_{2}$ band, solar heating due to absorption by $\mathrm{O}_{2}$ in the Schumann-Runge bands (SRB) and continuum (SRC), and by $\mathrm{O}_{2}, \mathrm{~N}_{2}$, and $\mathrm{O}$ in the extreme ultraviolet spectral region, parameterized chemical heating, molecular diffusion and viscosity, and ion drag. The current version of the eCMAM also includes comprehensive stratospheric chemistry [33] with radiatively interactive $\mathrm{O}_{3}$ and $\mathrm{H}_{2} \mathrm{O}$, a simplified ion chemistry scheme over a vertically limited domain, and non-LTE treatment of the near-infrared $\mathrm{CO}_{2}$ heating [34]. The Hines (1997 a, b) [35,36] non-orographic GWD scheme is used in this model. The model includes realistic tidal forcing due to radiative heating, convective processes, and latent heat release [37]. These processes have been shown to provide the forcing necessary to generate the migrating and nonmigrating tides [18,38-41].

Recently, the horizontal winds and temperature below $1 \mathrm{hPa}$ from this version of the eCMAM are nudged (i.e., relaxed) to the 6 hourly horizontal winds and temperature from the European Centre for Medium-Range Weather Forecasts (ECMWF) Re-Analysis (ERA) Interim reanalysis data [42] from January 1979 to June 2010 (thus named as eCMAM30). The nudging approach is designated to primarily constrain synoptic space and times scales in the model, which are well represented in the reanalysis data. This is accomplished by performing the relaxation in spectral space and applying it only to horizontal scales with $\mathrm{n} \leq \mathrm{T} 21$, where $\mathrm{n}$ is the total wavenumber. The nudging tendency has the form $-\left(X-X_{R}\right) / \tau_{0}$, where $\tau_{0}=24 \mathrm{~h}$ is the relaxational timescale, and $X$ and $X_{R}$ are, respectively, the model and reanalysis spectral vorticity, divergence, or temperature coefficients [43]. Linear interpolation is used to compute the reanalysis variables at intermediate times between adjacent $6 \mathrm{~h}$ intervals [44]. No nudging of chemistry fields is included in eCMAM30.

We validated the climatology of the background temperature and the diurnal tides (from DW5 to DE5) from eCMAM30 with SABER observations [45]. The model is doing a remarkable job in simulating the tides, and their altitudinal-latitudinal structures and seasonal variations are in very good agreement with SABER observations. The nudged version of the model shows better capability in simulating tides than the free-running version of the model. McLandress et al. (2013) [44] compared CMAM30 results with Aura MLS observations of mesospheric temperature, carbon monoxide (CO), and derived zonal wind during the 2006 and 2009 SSW and found good agreement. The nudged eCMAM has also been shown to represent well the dynamics of the upper mesosphere/lower thermosphere during some of the strongest SSWs in recent years [46]. 


\section{Results}

Since Figure 8 in Lieberman et al. (2015) [8] motivated this research, we reproduced Figure 8 with the eCMAM data to evaluate again the NOGAPS and SABER used in Lieberman et al. (2015). Figure 1 shows the evolution of stratospheric SPW1 geopotential height $(Z)$ amplitude, zonal mean temperature (T), and mesospheric DW2 T amplitude during December 2009 to February 2010 from the eCMAM30 run. Here, the eCMAM simulations for the same event are compared to both the NOGAPS model and SABER. It is obvious that all three fields (SPW1 Z amplitude, background T, DW2 T) compare very well with both NOGAPS and SABER. There are four SPW1 maxima during this period. DW2 T amplitude maximizes at the equator and presents similar maxima and its evolution appears to track the SPW1 Z amplitudes. As Lieberman et al. (2015) [8] has indicated, during this period, there is indeed a strong correlation between the SPW1 and DW2 amplitudes. SABER DW2 amplitudes shown in Figure 8 (fourth panel) of Lieberman et al. (2015) [8] are in good agreement with eCMAM as well. These results show that eCMAM produces realistic simulations and provides high quality data for the following analysis. We have also compared eCMAM DW2 T amplitudes and SABER observations in several other winters, and the agreement is as good as that in 2009-2010 (figures not shown).
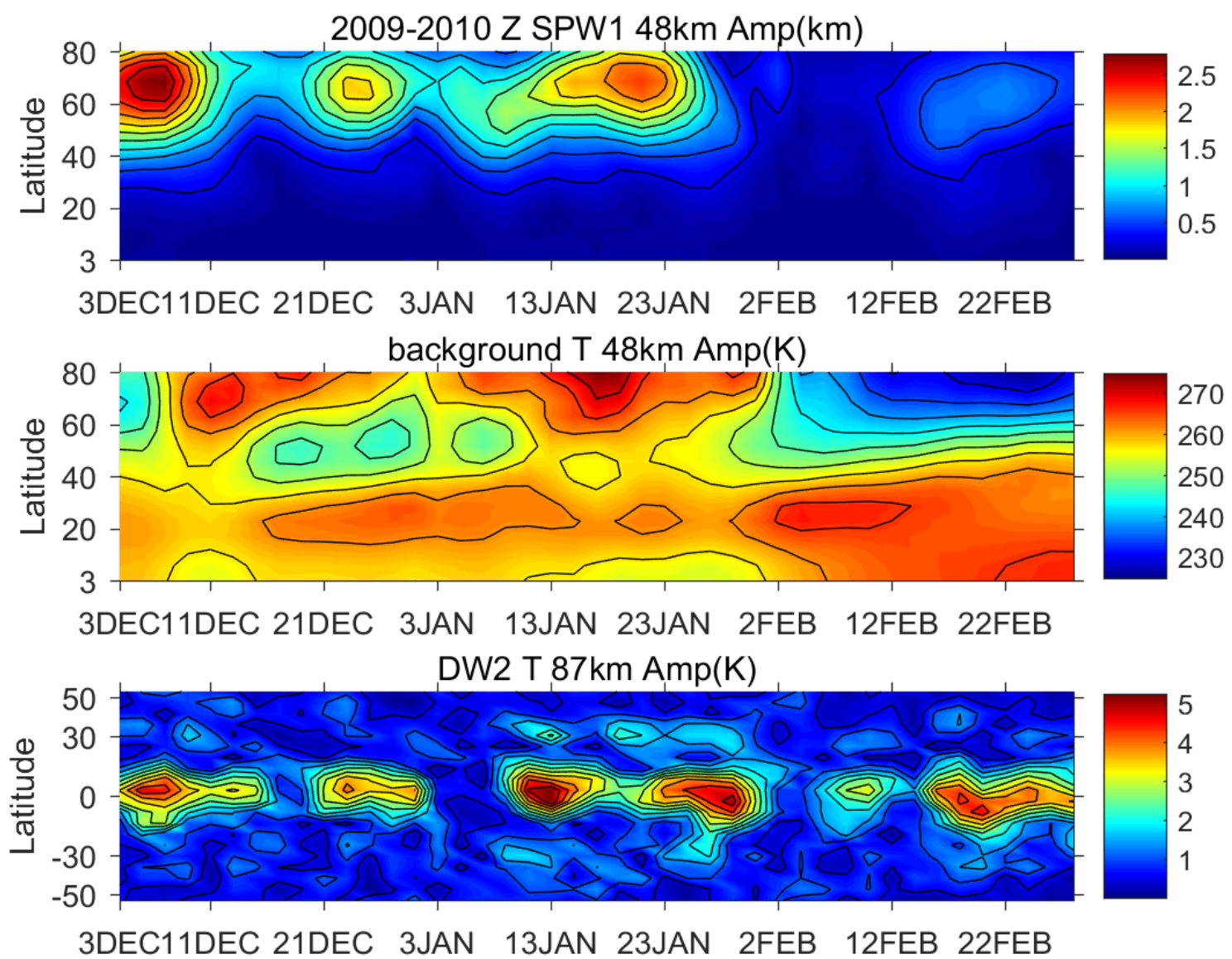

Figure 1. Same as Figure 8 in Leiberman et al. (2015) [8]. Latitude versus time variations in the eCMAM (extended Canadian Middle Atmosphere Model) parameters during December 2009-February 2010. (First panel) SPW1 (wavenumber 1) geopotential height (Z) amplitude at $\sim 48 \mathrm{~km}$, in kilometer. (Second panel) background temperature field (T). (Third panel) eCMAM DW2 (nonmigrating diurnal tide) temperature amplitude at $\sim 87 \mathrm{~km}$. 
Our question is that if the relationship observed between DW2 in the equatorial mesopause region and the SPW1 in the polar stratosphere in the 2009-2010 winter happens every year, or is it just a special case. Since the 2009-2010 winter has a strong split SSW event (stronger SPW2), does this mean we should see a stronger relationship between SPW1 and DW2 during winters with a displacement SSW event (stronger SPW1)? We answer this question by performing correlation analysis between the two waves for all winters from 1979 to 2010, and further separate each winter into no SSW event, minor SSW, displacement SSW, and split SSW events. We calculate correlations at zero lag between SPW1 and DW2. The SPW1 and DW2 amplitudes are calculated with a four-day average window and shifting by one-day. The time of the average window is longer than the time of propagation from stratosphere to mesopause (one to two days) for DW2, thus, lagged correlation is unnecessary.

The amplitude evolution of the SPW1 and DW2 can change with altitude adjacent to the 48 and $87 \mathrm{~km}$ as shown in Figure 1. Figure 2 gives an example of the SPW1 Z amplitude for the winter of 2009-2010 at 45, 48, and $51 \mathrm{~km}$. The overall latitudinal structure and time evolution are very similar at all three heights, but there are slight differences of the relative amplitude, which will affect the correlation coefficient depending on the height and latitude chosen. Figure 3 illustrates similar behavior observed in DW2 T field at 83, 85, 87, 89, and $91 \mathrm{~km}$.

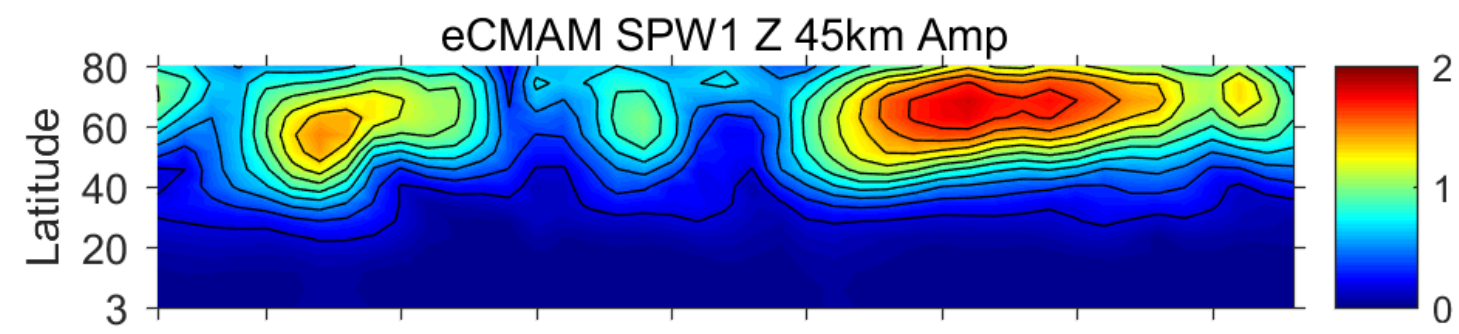

3DEC1DEC21DEC 3JAN 13JAN 23JAN 2FEB 12FEB 22FEB

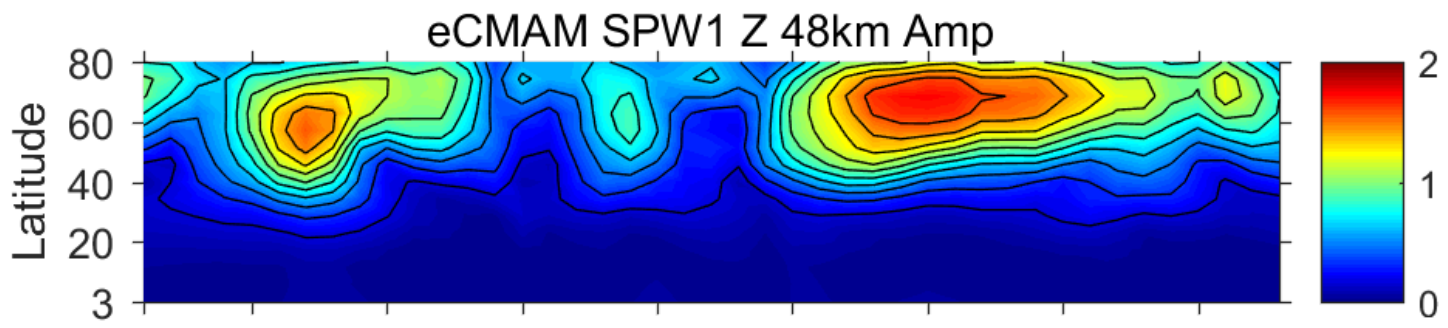

3DEG1DEC21DEC 3JAN 13JAN 23JAN 2FEB 12FEB 22FEB

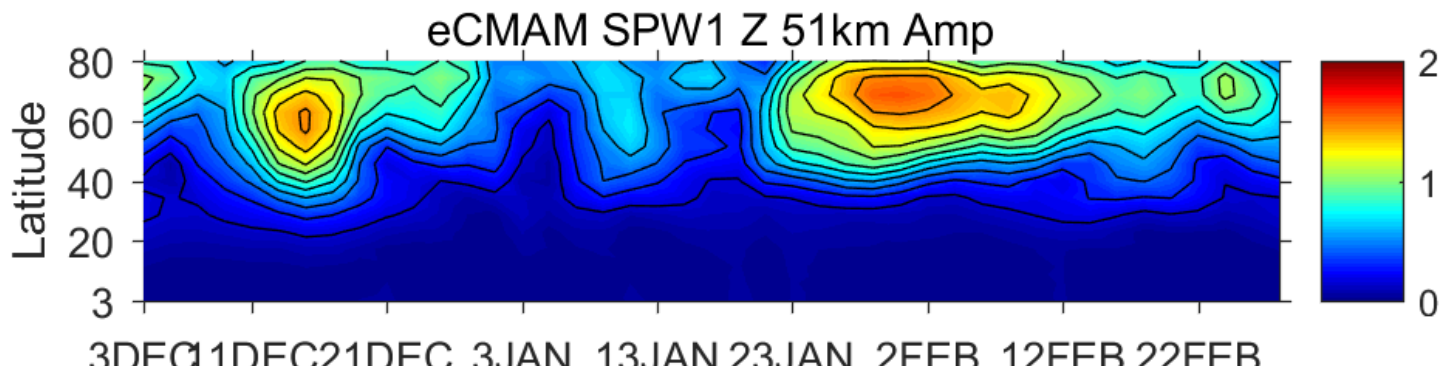

Figure 2. Latitude versus time variations of SPW1 $\mathrm{Z}$ amplitude in the eCMAM during December 2009-February 2010 at 45, 48, and $51 \mathrm{~km}$. 


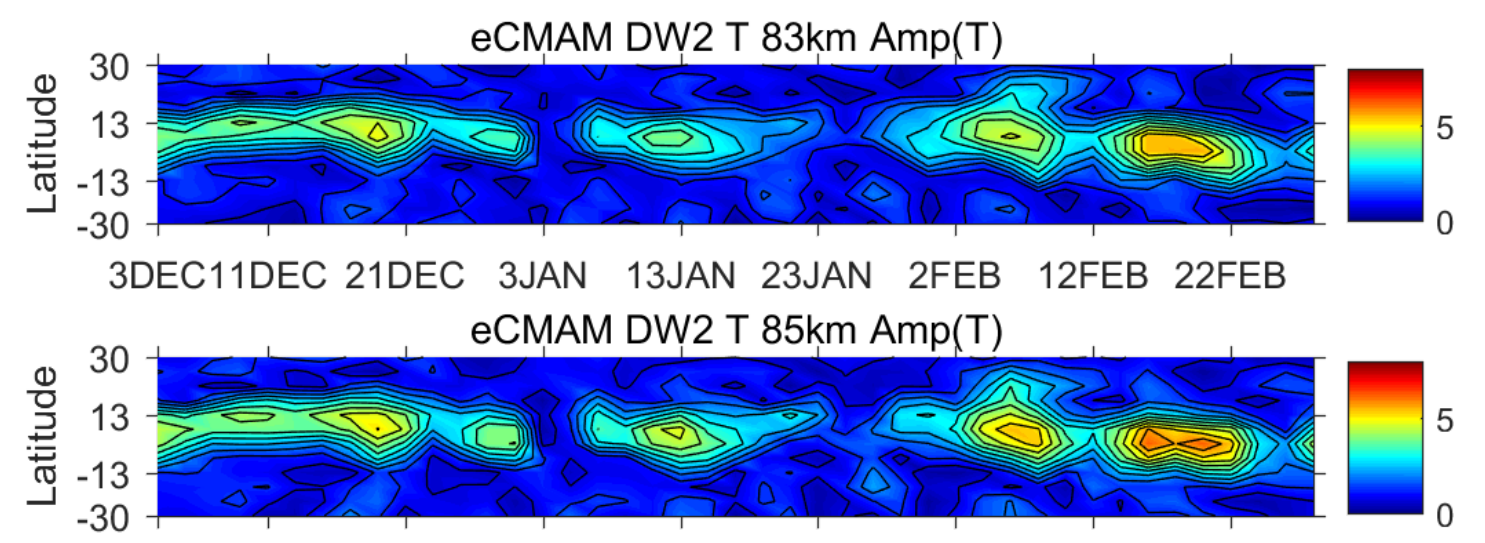

3DEC11DEC 21DEC 3JAN 13JAN 23JAN 2FEB 12FEB 22FEB
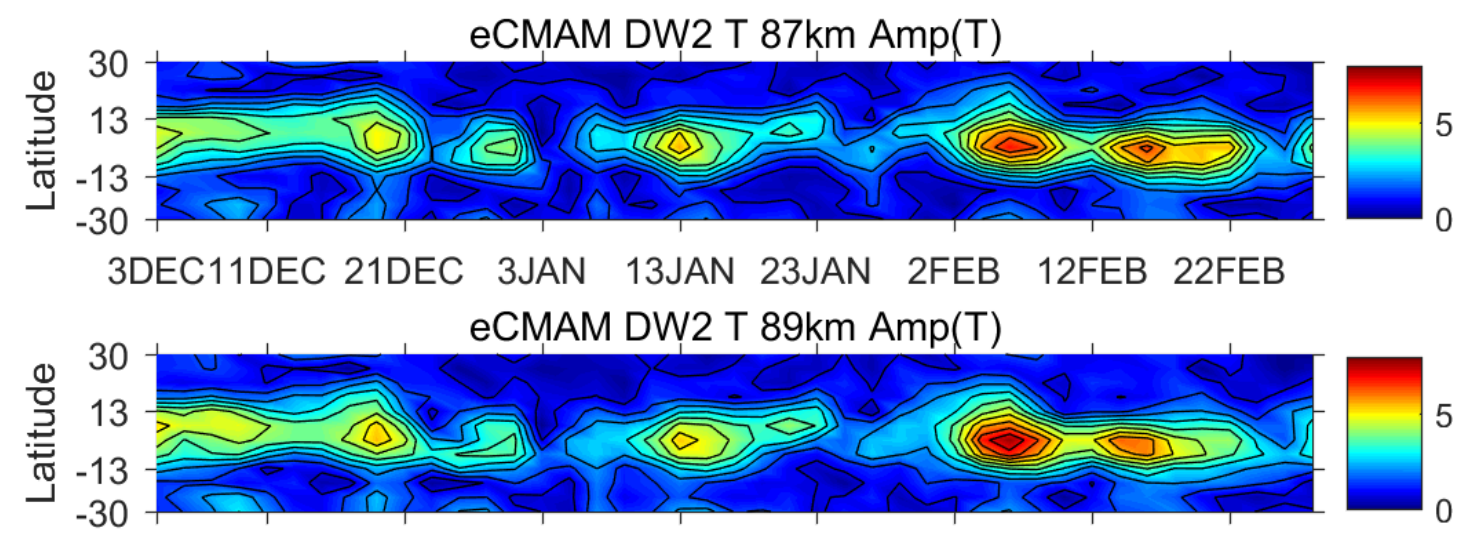

3DEC11DEC 21DEC 3JAN 13JAN 23JAN 2FEB 12FEB 22FEB

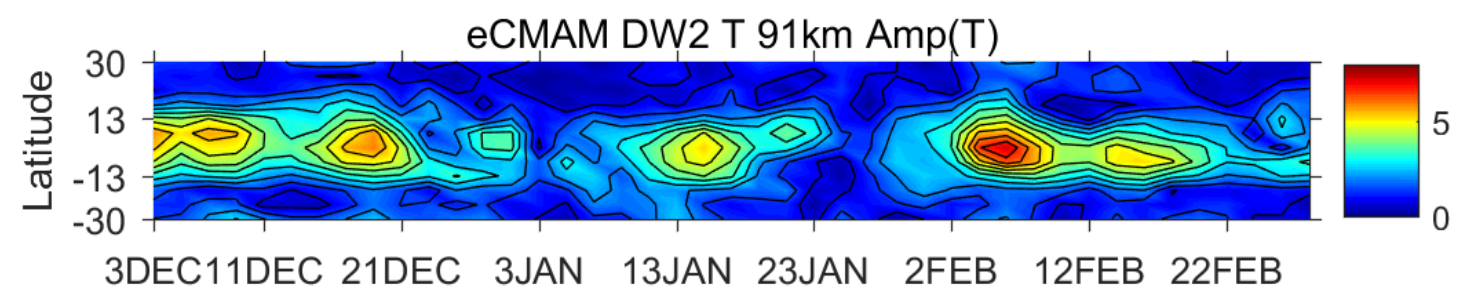

Figure 3. Same as Figure 2, but for the DW2 T field at 83, 85, 87, 89, and $91 \mathrm{~km}$.

To have a better quantitative evaluation of the correlations between SPW1 and DW2, our study computes correlation coefficients for different combinations of heights and latitudes. We select three heights $(45,48$, and $51 \mathrm{~km})$ and six latitudes $\left(47^{\circ}, 53^{\circ}, 58^{\circ}, 64^{\circ}, 69^{\circ}\right.$, and $\left.75^{\circ} \mathrm{N}\right)$ at which stratospheric SPW1 maximizes. Similarly, five heights $(83,85,87,89$, and $91 \mathrm{~km})$ and four latitudes $\left(8^{\circ} \mathrm{S}, 3^{\circ} \mathrm{S}, 3^{\circ}\right.$ $\mathrm{N}$, and $\left.8^{\circ} \mathrm{N}\right)$ are chosen for DW2 T field. Therefore, $360(3 \times 6 \times 5 \times 4)$ combinations of correlation coefficients are computed for each winter between the two waves. The maximum correlation is chosen to compare with other winters.

Figure 4 gives such an example for the 1992-1993 winter. The plots show the correlation coefficients between SPW1 and DW2 at all combinations of latitudes and heights. For example, the first column in Figure 4's left top panel represents the correlations between SPW1 at $45 \mathrm{~km}$ and $47^{\circ} \mathrm{N}$ and DW2 at 20 combinations of latitudes and heights denoted by different colors and marks specified in Figure 4's bottom right panel. The highest correlation (0.5003) for this particular winter occurs between SPW1 at $45 \mathrm{~km}$ and $75^{\circ} \mathrm{N}$ with DW2 at $89 \mathrm{~km}$ and $8^{\circ} \mathrm{S}$. These results show that the correlation can change significantly depending on chosen location. 


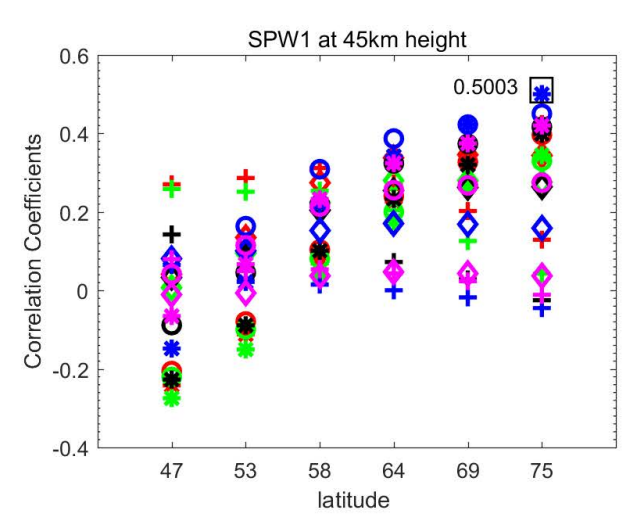

1992 December- 1993 February
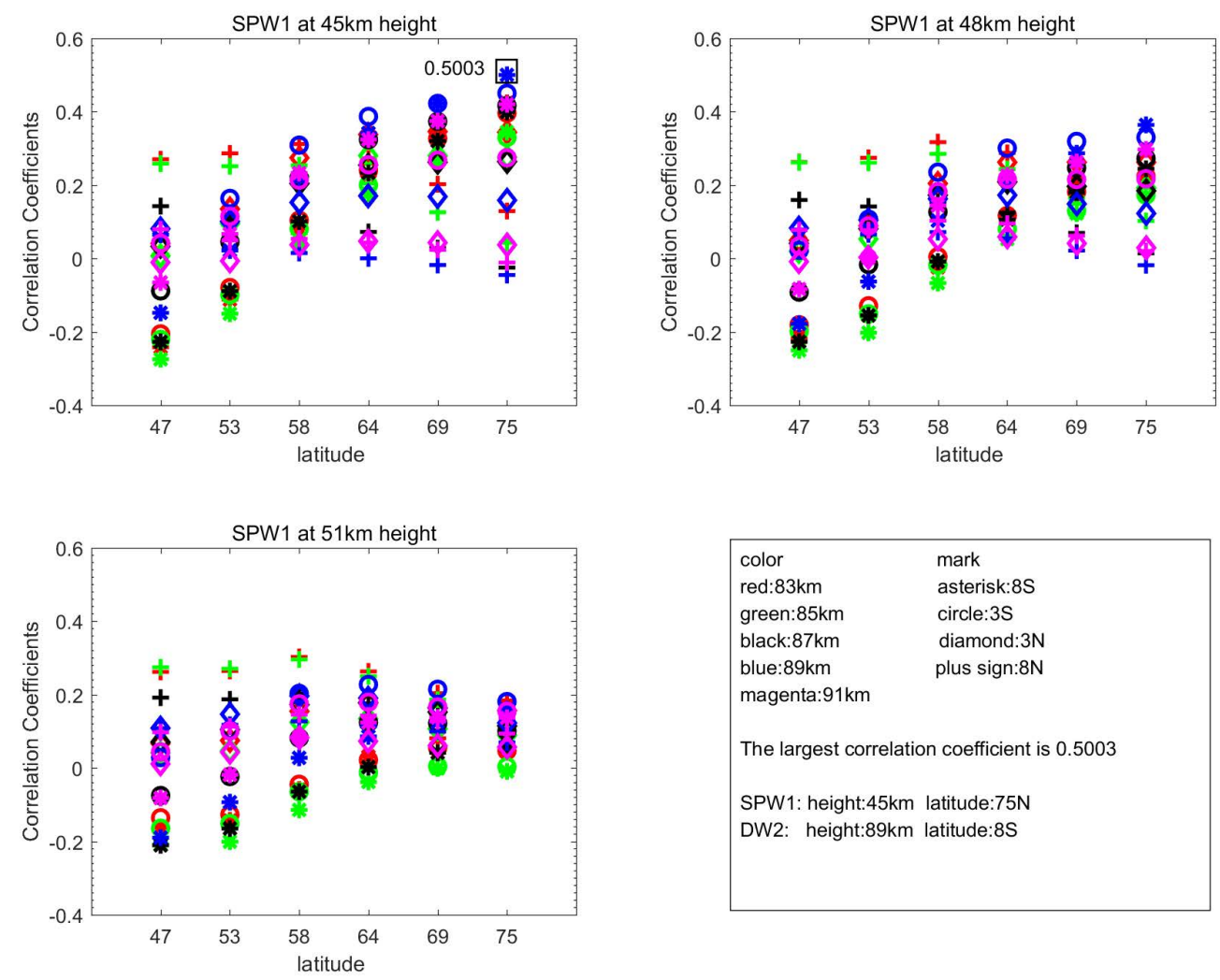

Figure 4. Correlation coefficients between SPW1 and DW2 at different combinations of latitudes and heights.

This procedure is repeated for all the winters and the highest correlation is sought between SPW1 and DW2 at locations where their maxima occur. We also separate the 31 winters (1979-2010) into four categories: Major SSW displacement, major SSW split, minor SSW, and no-SSW (Table 1). We define a stratospheric warming as the reversal of the zonal-mean zonal wind from westerly to easterly at $60^{\circ} \mathrm{N}, 10 \mathrm{hPa}$ to identify major stratospheric warming events [47-49]. Minor warming is defined when the meridional temperature gradient reverses for five consecutive days, but the zonal wind does not change direction (according to the World Meteorological Organization). The meridional temperature gradient is obtained by computing the zonal mean temperature for all latitudes from $60-90^{\circ} \mathrm{N}$, and then averaging them. The technique used to classify the polar vortex type follows that of Charlton and Polvani (2007) [48]. Cohen and Jones (2011) [49] did similar analysis on the National Centers for the Environmental Prediction-National Center for Atmospheric Research (NCEP-NCAR) reanalysis data, and the ERA- 40 and interim reanalysis, and found that the results were not sensitive to the reanalysis chosen.

Table 1. Classification of 31-winters (1979-2010) into SSW-D, SSW-S, Minor-SSW and No-SSW.

\begin{tabular}{cccc}
\hline $\begin{array}{c}\mathbf{( 8 )} \\
\text { SSW-D }\end{array}$ & $\begin{array}{c}\mathbf{( 8 )} \\
\text { SSW-S }\end{array}$ & $\begin{array}{c}\mathbf{( 4 )} \\
\text { Minor-SSW }\end{array}$ & $\begin{array}{c}\mathbf{( 1 1 )} \\
\text { No-SSW }\end{array}$ \\
\hline $1981-1982$ & $1984-1985$ & $1979-1980$ & $1982-1983$ \\
$1983-1984$ & $1987-1988$ & $1980-1981$ & $1985-1986$ \\
$1986-1987$ & $1988-1989$ & $1990-1991$ & $1989-1990$ \\
$1998-1999$ & $2000-2001$ & $1997-1998$ & $1991-1992$ \\
$2001-2002$ & $2002-2003$ & & $1992-1993$ \\
$2003-2004$ & $2005-2006$ & & $1993-1994$ \\
$2006-2007$ & $2008-2009$ & & $1994-1995$ \\
$2007-2008$ & $2009-2010$ & & $1995-1996$ \\
& & & $1996-1997$ \\
& & & $1999-2000$ \\
& & & $2004-2005$ \\
\hline
\end{tabular}


The eCMAM lower atmosphere was nudged to ERA-interim reanalysis. As shown in Table 1, out of the 31 winters between 1979 and 2010, there are eight winters that are major SSW displacement, eight that are major SSW split events, four that had minor SSW, and 11 winters with no SSW events. Figure 5 provides the highest correlations between SPW1 in the polar stratosphere and DW2 in the equatorial mesopause region for $31 \mathrm{NH}$ winters from 1979 to 2010. Red bars represent all the winters with an SSW-D event, green is for SSW-S events, black for no-SSW winters, and yellow for minor SSW events (corresponding to Table 1). The significance test is conducted at the $95 \%$ confidence level with Monte Carlo white noise time series and presented in magenta.

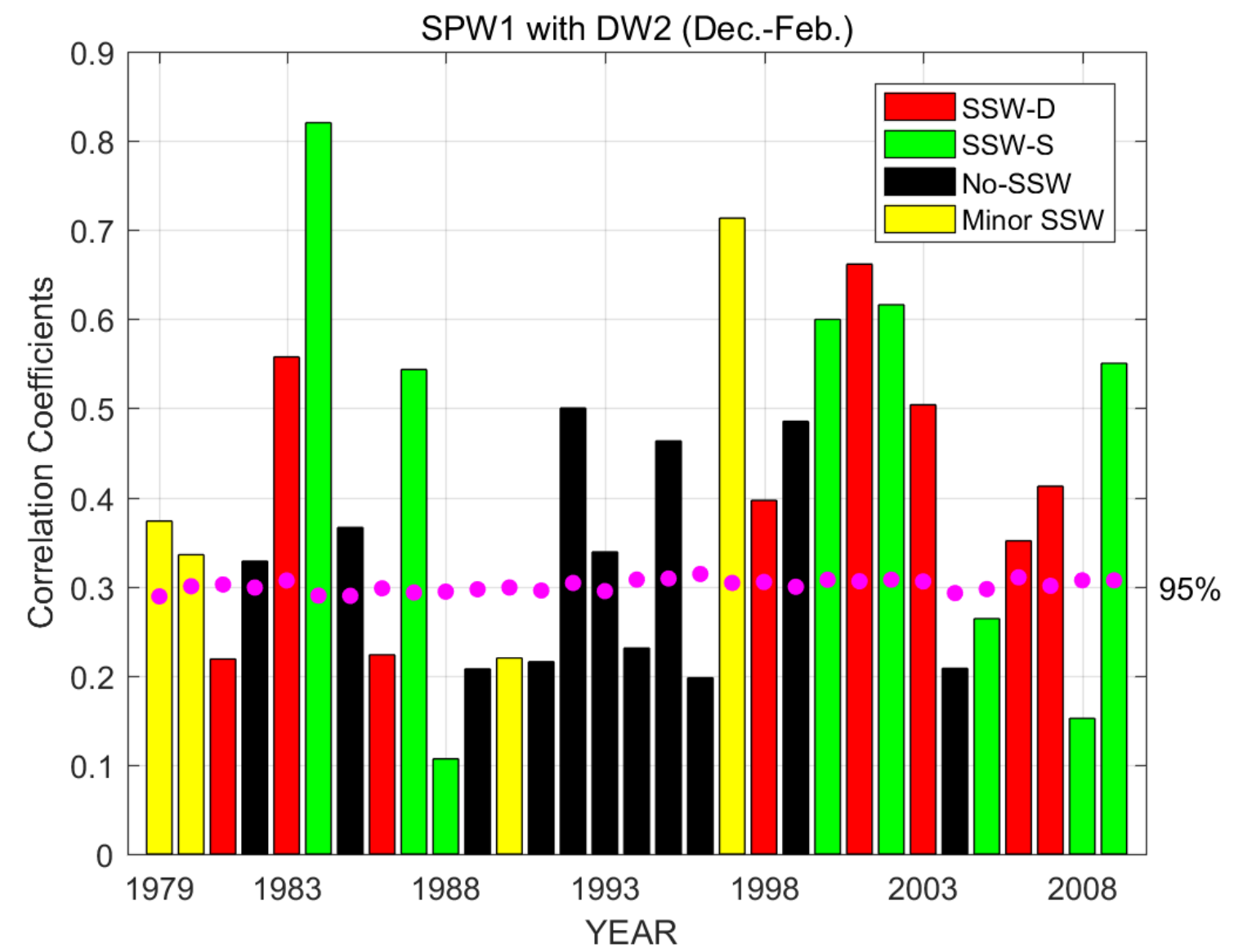

Figure 5. Highest correlations between SPW1 and DW2 for 31-winters from 1979 to 2010 under different SSW (sudden stratospheric warming) scenarios.

It can be seen that 20 out of 31 years $(65 \%)$ have passed the significance test. The correlation varies significantly from year to year. Three out of four minor-SSW (75\%), six out of eight SSW-D (75\%), five out of eight (62.5\%) SSW-S, and six out of 11 no-SSW (54.5\%) winters show significant correlations between the two waves. The highest correlation (0.82) occurred in the 1984-1985 winter, which has an SSW split event. The winter of 2009-2010 (SSW-S) presented by Lieberman et al. (2015) [8] shows a decent high correlation of 0.55. The lowest correlation is 0.1 for the winter of 1988-1989 (SSW-S). The average correlation for all SSW-D winters is 0.42 , while it is 0.46 for SSW-S winters. The average is 0.41 and 0.32 for minor-SSW and no-SSW winters, respectively. We further investigate the relationship between SSW categories and the correlations through a student t-test. There is no significant correlation difference detected among all four SSW categories (table not shown). This result indicates that the nonlinear interactions between these two waves are not particularly stronger during winters with SSW events, or have preference over the type of the SSW events. However, there are overall significant correlations between the two waves in $65 \%$ of all winters (out of the 31 -winter statistics). 
Figure 6 gives the highest correlation between the two waves in the winter of 1984-1985. In a similar format as Figure 1, and Figure 8 in Lieberman et al. (2015), Figure 6 shows the evolution of stratospheric SPW1 geopotential height (Z) amplitude, zonal mean temperature (T), and mesospheric DW2 T amplitude from December 1984 to February 1984 from eCMAM30. There is an SSW-S event in December 1984. The time evolution of the two waves matches very well with multi-peaks during the warming and one distinct peak after the warming. The correlation between these two waves is even higher than the 2009-2010 winter shown in Lieberman et al. (2015) [8]. On the other hand, Figure 7 is the same as Figure 6, but shows the lowest correlation winter between the two waves: 1988-1989. There was also an SSW-S event that happened later and lasted longer than the one in 1984-1985. The time evolution between the waves does not match well with the correlation of 0.01 . As shown in Figure 7, there are seven peaks in the SPW1 and nine peaks in the DW2. The duration of each peak does not match well between the two waves. A closer look at the zonal mean temperature fields between the two winters reveals that in 1984-1985, the warming peaks at around 20 December, although the polar region got cooler afterwards; however, there is an equatorward propagation of the warming, which lasted for the rest of the winter. A similar feature is also observed in the winter of 2009-2010 (Figure 1). Whereas in the winter of 1988-1989, the warming was more confined in the polar region, and there was no equatorward propagation. This might be the reason why these two winters are so different. The subject of source mechanisms deserves a detailed future study, but is beyond the scope of the current paper.

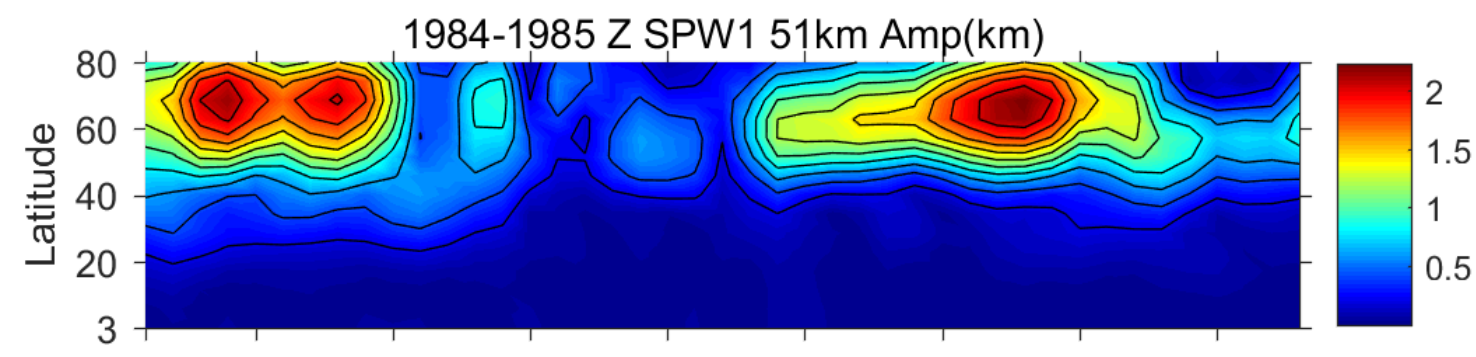

3DEC11DEC 21DEC 3JAN 13JAN 23JAN 2FEB 12FEB 22FEB

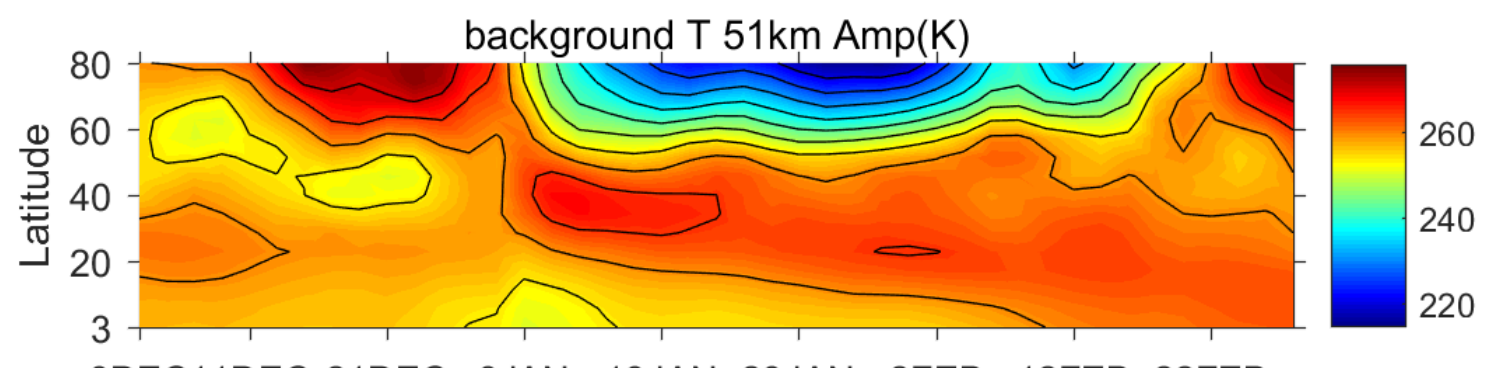

3DEC11DEC 21DEC 3JAN 13JAN 23JAN 2FEB 12FEB 22FEB

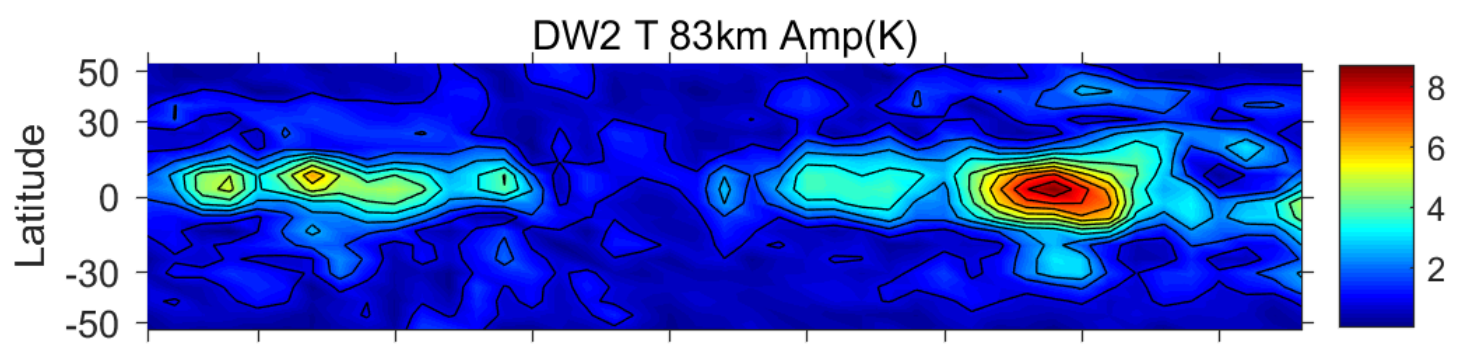

3DEC11DEC 21DEC 3JAN 13JAN 23JAN 2FEB 12FEB 22FEB

Figure 6. Same as Figure 1, but for the winter of 1984-1985: The highest correlation between SPW1 and DW2. 

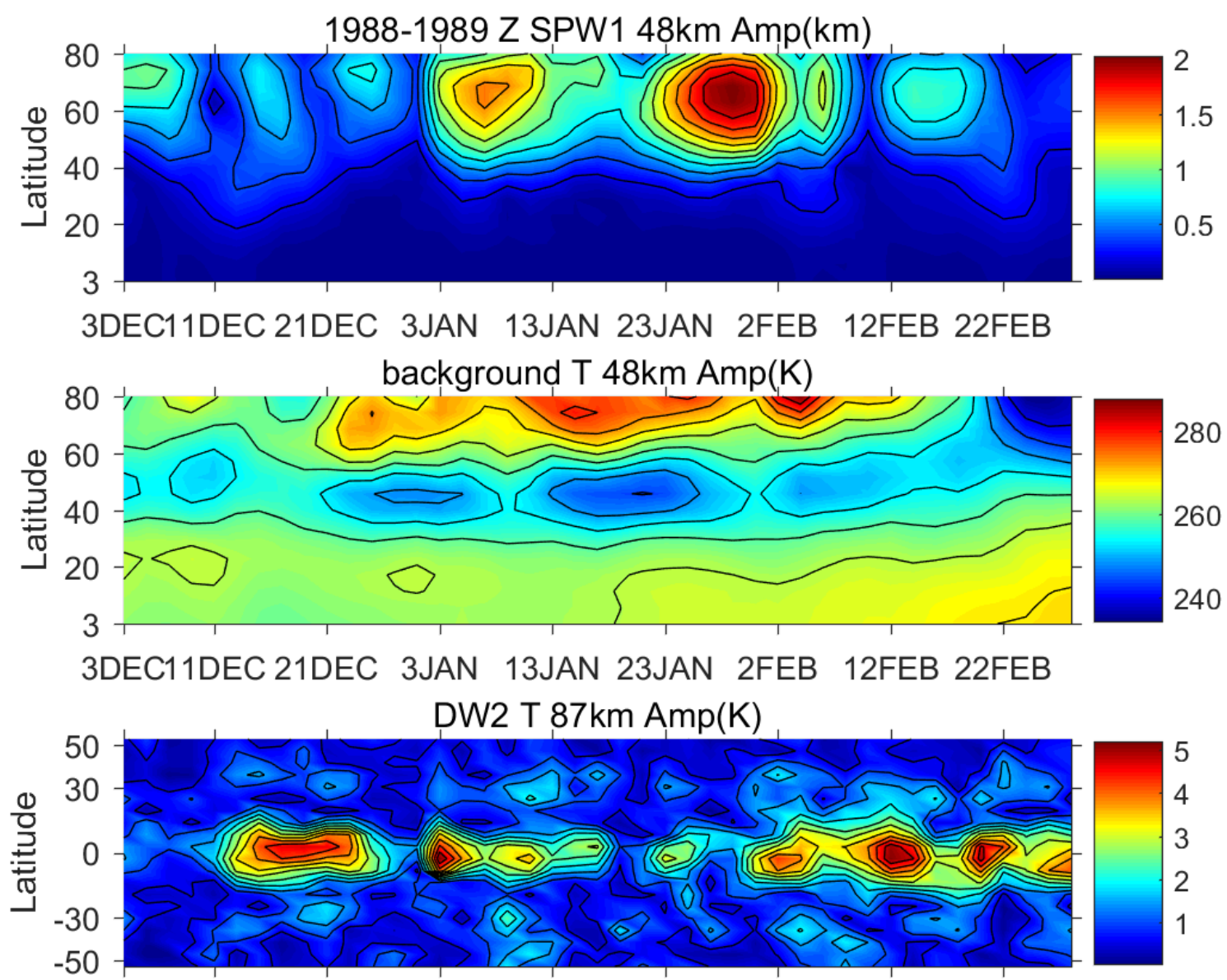

3DEC11DEC 21DEC 3JAN 13JAN 23JAN 2FEB 12FEB 22FEB

Figure 7. Same as Figure 1, but for the winter of 1988-1989: The lowest correlation between SPW1 and DW2.

\section{Discussion}

The other 'child' wave from the SPW-DW1 interaction is DS0. Lieberman et al. (2015) [8] mainly focused on DW2 and little about DS0 is presented. DS0 maximized around $30^{\circ} \mathrm{N}$ and $110 \mathrm{~km}$. We did similar plots for DS0 as the DW2 presented in the paper (not shown). The DS0 amplitude had more variability than DW2 in the winter of 2009-2010, and the tracking of the SPW1 amplitude was not as obvious as that for DW2. This is probably the reason that Lieberman et al. (2015) [8] mainly focused on DW2 instead of DS0. We calculated the correlation between DS0 and SPW1 for the winter of 2009-2010 and it is around 0.45 compared to $~ 0.55$ for SPW1 and DW2. We calculated the correlations between SPW1 and DS0 for all 31 winters. The mean correlation for SPW1/DS0 and SPW1/DW2 was very similar (both around 0.39). Surprisingly, there are more winters that SPW1 showed significant correlations with DS0 (24 winters) than DW2 (20 winters). Overall, we do see that SPW1 leaves a significant imprint on both DW2 and DS0 in about half of all the winters (16 out of 31). The rest of the 15 winters is separated into winters (3) that had no significant correlations for neither of the two, and winters (12) that only one child wave had a significant correlation with SPW1.

Both DS0 and DW2 showed no preference over SSW types in terms of correlation with SPW1. The highest correlation between SPW1 and DW2 was the winter of 1984-1985, which had a split SSW event. The second highest correlation happened in a minor SSW winter of 1997-1998, and the third highest is the 2001-2002 winter with a displacement SSW event. The winter of 2009-2010 showed in Lieberman et al. (2015) [8] had a split SSW event. Since SSW-D years have stronger SPW1 than normal, one would expect stronger interactions between SPW1 and DW2. However, this seems not to be the case. Similarly, SPW2 was stronger during SSW-S, and we assume that similar conclusions apply to 
the SPW2 and DW1 interaction (child wave DE1 and DW3): The interaction between SPW2 and DW1 was not particularly stronger in the winters with SSW-S events. This assumption will be tested in future work.

This paper shows that nonlinear interaction of SPW1 and DW1 is indeed a source for DW2 and DS0. Significant correlations were observed between the child waves and SPW1 in the majority of the winters. However, the correlations change year to year, implying the strength of the nonlinear interaction changes year to year. Thus, the first significant question is: What governs the strength of the nonlinear interaction? Since the DW1 structure is essentially fixed and fairly steady, the strength of the nonlinear interaction should lie within the structure of the SPW1. Maybe the background is more favorable for SPW1 to propagate equatorward than other years to interact with DW1. Lieberman et al. (2015) [8] investigated the advective process that couple SPW1 and DW2 and found that meridional advection of SPW1 zonal momentum by DW1 (migrating diurnal tide) is a significant source of lower thermosphere DW2 for the winter of 2009-2010. To investigate the difference of nonlinear forcing in every winter, this approach should extended to every winter, and their magnitudes and shapes compared. Furthermore, the change in SPW1 that governs the strength of the nonlinear interaction seems to be unrelated to the type of SSW.

Besides the nonlinear interaction, DW2 has another significant source: Latent heat. The relative role of these two sources is another challenging question. One needs to first examine if latent heat source for DW2 has significant year-to-year variation. We have learned from this study that the nonlinear interaction source presents large changes year-to-year. Similar correlation analysis should be performed between DW2 and DW2 latent heat. The physical mechanisms that govern the variability of DW2 will be investigated vigorously in a following study.

\section{Conclusions}

Inspired by Lieberman et al. (2015) [8], this paper investigated if the time evolution of the SPW1 in the polar stratosphere and DW2 in the equatorial mesopause matches in every NH winter. In theory, during an SSW-D event, the SPW1 is particularly stronger, which can possibly result in a stronger interaction between the two waves. This paper also investigated if the time evolution of these two waves matches better for winters with an SSW-D event. We used a 31.5-year (1979-2010) run from the eCMAM. The lower atmosphere of the eCMAM was nudged to the ERA-interim reanalysis data. The eCMAM simulations compared well with the NOGAPS model and SABER for the 2009-2010 winter shown in Lieberman et al. (2015) [8].

Correlation coefficients were calculated between the two waves at locations around their maximum amplitudes, and highest correlations were recorded and compared among all winters. The results show that significant correlations were present between the two waves in $20(65 \%)$ winters in 31 years from 1979 to 2010. This study shows that nonlinear interaction of SPW1 and DW1 was indeed a source for DW2 and DS0. Significant correlations were observed between the child waves and SPW1 in the majority of the winters. However, the correlations change year to year, implying the strength of the nonlinear interaction changed year to year.

We then separated all winters into four categories: SSW-displacement, SSW-split, minor-SSW, and no-SSW. Significant correlations were present in all categories of winters: Three out of four minor-SSW (75\%), six out of eight SSW-D (75\%), five out of eight SSW-S $(62.5 \%)$, and six out of 11 no-SSW (54.5\%). Student t-test shows that there is no significant difference among the four categories in terms of correlations between the two waves. Although SPW1 was usually stronger during a SSW-D winter, this does not warrant a stronger interaction with DW2. This implies that the SPW1 structure change that governs the strength of the nonlinear interaction year-to-year was irrelevant to the type of SSW. Vigorous study of the physical mechanisms that governs the DW2 variability will be pursued in a future study and must also include the latent heating source. 
Author Contributions: Conceptualization: J.D.; Methodology: X.N., X.Z. and J.D.; Formal Analysis: X.N.; Writing-Original draft preparation: X.Z. and X.N.; Writing-Review \& Editing, J.D.; Supervision, J.D.; Project Administration, J.D.; Funding Acquisition, J.D.

Funding: This research is funded by NSF aeronomy program grant NO. 1453943. The eCMAM30 data used in this article may be obtained by registering with the Canadian Centre for Climate Modelling and Analysis (CCCma) using the online form: http:/ / www.cccma.ec.gc.ca/data/application.shtml.

Acknowledgments: J.D. is supported by NSF aeronomy program grant NO. 1453943. The eCMAM30 data used in this article may be obtained by registering with the Canadian Centre for Climate Modelling and Analysis (CCCma) using the online form: http://www.cccma.ec.gc.ca/data/application.shtml.

Conflicts of Interest: The authors declare no conflicts of interest.

\section{References}

1. The NRC 2013-2022 Decadal Survey in Solar and Space 8-20, p. 2012. Available online: https: //sites.nationalacademies.org/cs/groups/ssbsite/documents/webpage/ssb_087106.pdf (accessed on 12 October 2018).

2. Pancheva, D.V.; Mukhtarov, P.J.; Shepherd, M.G.; Mitchell, N.J.; Fritts, D.C.; Riggin, D.M.; Franke, S.J.; Batista, P.P.; Abdu, M.A.; Batista, I.S.; et al. Two-day wave coupling of the low-latitude atmosphere-ionosphere system. J. Geophys. Res. 2006, 111, A07313. [CrossRef]

3. Lieberman, R.S.; Riggin, D.M.; Ortland, D.A.; Nesbitt, S.W.; Vincent, R.A. Variability of mesospheric diurnal tides and tropospheric diurnal heating during 1997-1998. J. Geophys. Res. 2007, 112, D20110. [CrossRef]

4. Ekanayake, E.M.P.; Aso, T.; Miyahara, S. Background wind effect on propagation of nonmigrating diurnal tides in the middle atmosphere. J. Atmos. Sol. Terr. Phys. 1997, 59, 401-429. [CrossRef]

5. Teitelbaum, H.; Vial, F. On tidal variability induced by nonlinear interaction with planetary waves. J. Geophys. Res. 1991, 96, 14169-14178. [CrossRef]

6. McLandress, C.; Ward, W.E. Tidal/gravity wave interactions and their influence on the large-scale dynamics of the middle atmosphere: Model results. J. Geophys. Res. 1994, 99, 8139-8155. [CrossRef]

7. Pancheva, D.; Merzlyakov, E.; Mitchell, N.J.; Portnyagin, Y.; Manson, A.H.; Jacobi, C.; Meek, C.E.; Luo, Y.; Clark, R.R.; Hocking, W.K.; et al. Global-scale tidal variability during the PSMOS campaign for June-August 1999: Interaction with planetary waves. J. Atmos. Sol. Terr. Phys. 2002, 64, 1865. [CrossRef]

8. Lieberman, R.S.; Riggin, D.M.; Ortland, D.A.; Oberheide, J.; Siskind, D.E. Global observations and modeling of nonmigrating diurnal tides generated by tide-planetary wave interactions. J. Geophys. Res. Atmos. 2015, 120, 11419-11437. [CrossRef]

9. Forbes, J.M.; Makarov, N.A.; Portnyagin, Y. First results from the meteor radar at South Pole-A large 12-hour oscillation with zonal wave-number one. Geophys. Res. Lett. 1995, 22, 3247-3250. [CrossRef]

10. Talaat, E.R.; Lieberman, R. Non-migrating diurnal tides in mesospheric and lower thermospheric winds and temperatures. J. Atmos. Sci. 1999, 56, 4073. [CrossRef]

11. Miyahara, S.; Miyoshi, Y.; Yamashita, K. Variations of migrating and non-migrating atmospheric tides simulated by a middle atmosphere general circulation model. Adv. Space Res. 1999, 24, 1549-1558. [CrossRef]

12. Hagan, M.E.; Roble, R.G. Modeling diurnal tidal variability with the National Center for Atmospheric Research thermosphere-ionosphere-mesosphere-electrodynamics general circulation model. J. Geophys. Res. 2001, 106, 24869-24882. [CrossRef]

13. Coll, M.A.I.; Forbes, J.M. Nonlinear interactions in the upper atmosphere: The $\mathrm{s}=1$ and $\mathrm{s}=3$ non-migrating semidiumal tides. J. Geophys. Res. 2002, 107, 1157.

14. Liu, H.-L.; Li, T.; She, C.-Y.; Oberheide, J.; Wu, Q.; Hagan, M.E.; Xu, J.; Roble, R.G.; Mlynczak, M.G.; Russell, J.M., III. Comparative study of short-term diurnal tidal variability. J. Geophys. Res. 2007, 112, D18108. [CrossRef]

15. Yamashita, K.; Miyahara, S.; Miyoshi, Y.; Kawano, K.; Ninomiya, J. Seasonal variation of non-migrating semidiurnal tide in the polar MLT region in a general circulation model. J. Atmos. Sol. Terr. Phys. 2002, 64, 1083-1094. [CrossRef]

16. Chang, L.C.; Palo, S.E.; Liu, H.L. Short-term variability in the migrating diurnal tide caused by interactions with the quasi 2 day wave. J. Geophys. Res. 2011, 116, D12112. [CrossRef] 
17. Hall, C.; Xu, X.; Manson, A.; Meek, C.; Chshyolkova, T.; Drummond, J.R.; Jacobi, C.; Riggin, D.; Hibbins, R.E.; Tsutsumi, M.; et al. Relationship between variability of the semidiurnal tide in the Northern Hemisphere mesosphere and quasi-stationary planetary waves throughout the global middle atmosphere. Ann. Geophys. 2009, 27, 4239-4256. [CrossRef]

18. Du, J.; Ward, W.E.; Cooper, F.C. The Character of Polar Tidal Signatures in the extended Canadian Middle Atmosphere Model (eCMAM). J. Geophys. Res. Atmos. 2014. [CrossRef]

19. Matsuno, T. A dynamical model of the stratospheric sudden warming. J. Atmos. Sci. 1971, 28, 1479-1494. [CrossRef]

20. Liu, H.L.; Roble, R.G. A study of a self-generated stratospheric sudden warming and its mesospheric-lower thermospheric impacts using the coupled TIME-GCM/CCM3. J. Geophys. Res. 2002, 107, 4695. [CrossRef]

21. Pancheva, D.V.; Mukhtarov, P.; Andonov, B. Nonmigrating tidal activity related to the sudden stratospheric warming in the Arctic winter of 2003/2004. Ann. Geophys. 2009, 27, 975-987. [CrossRef]

22. Liu, H.-L.; Wang, W.; Richmond, A.D.; Roble, R.G. Ionospheric variability due to planetary waves and tides for solar minimum conditions. J. Geophys. Res. 2010, 115, A00G01. [CrossRef]

23. Pedatella, N.M.; Forbes, J.M. Evidence for stratosphere sudden warming-ionosphere coupling due to vertically propagating tides. Geophys. Res. Lett. 2010, 37, L11104. [CrossRef]

24. Sridharan, S.; Sathishkumar, S.; Gurubaran, S. Variabilities of mesospheric tides and equatorial electrojet strength during major stratospheric warming events. Ann. Geophys. 2009, 27, 4125-4130. [CrossRef]

25. Sridharan, S.; Sathishkumar, S.; Gurubaran, S. Variabilities of mesospheric tides during sudden stratospheric warming events of 2006 and 2009 and their relationship with ozone and water vapour. J. Atmos. Sol. Terr. Phys. 2012, 78-79, 108-115. [CrossRef]

26. Goncharenko, L.P.; Chau, J.L.; Liu, H.-L.; Coster, A.J. Unexpected connections between the stratosphere and ionosphere. Geophys. Res. Lett. 2010, 37, L10101. [CrossRef]

27. Lima, L.M.; Alves, E.O.; Batista, P.P.; Clemesha, B.R.; Medeiros, A.F.; Buriti, R.A. Sudden stratospheric warming effects on the mesospheric tides and 2-day wave dynamics at 7S. J. Atmos. Sol. Terr. Phys. 2012, 78-79, 99-107. [CrossRef]

28. Ehrmann, T. Identification and Classification of Stratospheric Sudden Warming Events. Master's Thesis, Embry-Riddle Aeronautical University, Daytona Beach, FL, USA, 2012.

29. Beagley, S.R.; McLandress, C.; Fomichev, V.I.; Ward, W.E. The extended Canadian Middle Atmosphere Model. Geophys. Res. Lett. 2000, 27, 2529-2532. [CrossRef]

30. Beagley, S.R.; Boone, C.D.; Fomichev, V.I.; Jin, J.J.; Semeniuk, K.; McConnell, J.C.; Bernath, P.F. First multi-year occultation observations of $\mathrm{CO}_{2}$ in the MLT by ACE satellite: Observations and analysis using the extended CMAM. Atmos. Chem. Phys. 2010, 10, 1133-1153. [CrossRef]

31. Fomichev, V.I.; Ward, W.E.; Beagley, S.R.; McLandress, C.; McConnell, J.C.; McFarlane, N.A.; Shepherd, T.G. Extended Canadian Middle Atmosphere Model: Zonal-mean climatology and physical parameterizations. J. Geophys. Res. 2002, 107, 4087. [CrossRef]

32. McLandress, C.; Ward, W.E.; Fomichev, V.I.; Semeniuk, K.; Beagley, S.R.; McFarlane, N.A.; Shepherd, T.G. Large-scale dynamics of the mesosphere and lower thermosphere: An analysis using the extended Canadian Middle Atmosphere Model. J. Geophys. Res. 2006, 111, D17111. [CrossRef]

33. De Grandpré, J.; Beagley, S.R.; Fomichev, V.I.; Griffioen, E.; Mc-Connell, J.C.; Medvedev, A.S.; Shepherd, T.G. Ozone climatology using interactive chemistry: Results from the Cana-dian Middle Atmosphere Model. J. Geophys. Res. 2000, 105, 26475-26492. [CrossRef]

34. Ogibalov, V.P.; Fomichev, V.I. Parameterization of solar heating by the near $\mathrm{IR}^{\mathrm{CO}_{2}}$ bands in the mesosphere. Adv. Space Res. 2003, 32, 759-764. [CrossRef]

35. Hines, C.O. Doppler-spread parameterization of gravity-wave momentum deposition in the middle atmosphere, 1, basic formulation. J. Atmos. Solar. Terr. Phys. 1997, 59, 371-386. [CrossRef]

36. Hines, C.O. Doppler-spread parameterization of gravity-wave momentum deposition in the middle atmosphere, 2, broad and quasi monochromatic spectra, and implementation. J. Atmos. Sol. Terr. Phys. 1997, 59, 387-400. [CrossRef]

37. Scinocca, J.F.; McFarlane, N.A. The variability of the modeled tropical precipitation. J. Atmos. Sci. 2004, 61, 1993-2015. [CrossRef]

38. McLandress, $\mathrm{C}$. The seasonal variation of the propagating diurnal tide in the mesosphere and lower thermosphere. Part I: The role of gravity waves and planetary waves. J. Atmos. Sci. 2002, 59, 893. [CrossRef] 
39. Ward, W.E.; Fomichev, V.I.; Beagley, S. Nonmigrating tides in equinox temperature fields from the Extended Canadian Middle Atmosphere Model (CMAM). Geophys. Res. Lett. 2005, 32, L03803. [CrossRef]

40. Du, J.; Ward, W.E.; Oberheide, J.; Nakamura, T.; Tsuda, T. Semidiurnal tides from the Extended Canadian Middle Atmosphere Model (CMAM) and comparisons with TIMED Doppler Interferometer (TIDI) and meter radar observations. J. Atmos. Sol. Terr. Phys. 2007, 69, 2159-2202. [CrossRef]

41. Du, J.; Ward, W.E. Terdiurnal tide in the extended Canadian Middle Atmospheric Model (CMAM). J. Geophys. Res. 2010, 115, D24106. [CrossRef]

42. Uppala, S.M.; Kållberg, P.W.; Simmons, A.J.; Andrae, U.; Bechtold, V.D.C.; Fiorino, M.; Gibson, J.K.; Haseler, J.; Hernandez, A.; Kelly, G.A.; et al. The ERA-40 Re-Analysis. Q. J. R. Meteorol. Soc. 2005, 131, 2961-3012. [CrossRef]

43. Kharin, V.V.; Scinocca, J.F. The impact of model fidelity on seasonal predictive skill. Geophys. Res. Lett. 2012, 39, L18803. [CrossRef]

44. McLandress, C.; Scinocca, J.F.; Shepherd, T.G.; Reader, M.C.; Manney, G.L. Dynamical Control of the Mesosphere by Orographic and Nonorographic Gravity Wave Drag during the Extended Northern Winters of 2006 and 2009. J. Atmos. Sci. 2013, 70, 2152-2169. [CrossRef]

45. Gan, Q.; Du, J.; Ward, W.E.; Beagley, S.R.; Fomichev, V.I.; Zhang, S. Climatology of the diurnal tides from eCMAM30 (1979 to 2010) and its comparison with SABER. Earth Planets Space 2014, 66, 103. [CrossRef]

46. Shepherd, M.G.; Beagley, S.R.; Fomichev, V.I. Stratospheric warming influence on the mesosphere/lower thermosphere as seen by the extended CMAM. Ann. Geophys. 2014, 32, 589-608. [CrossRef]

47. Manney, G.L.; Kruger, K.; Sabutis, J.L.; Sena, S.A.; Pawson, S. The remarkable 2003-2004 winter and other recent warm winters in the Arctic stratosphere since the late 1990s. J. Geophys. Res. 2005, 110, D04107. [CrossRef]

48. Charlton, A.J.; Polvani, L.M. A new look at stratospheric sudden warmings. Part I: Climatology and modeling benchmarks. J. Clim. 2007, 20, 449-469. [CrossRef]

49. Cohen, J.; Jones, J. Tropospheric precursors and stratospheric warmings. J. Clim. 2011, 24, 6562-6572. [CrossRef] 